\title{
Transport-Controlled Dissolution in an Evolving Fracture: The Extended Purday Solution and Fracture Flow Tests
}

\author{
Wei Li, ${ }^{1}$ John T Germaine ${ }^{2}$ Herbert H. Einstein, ${ }^{1}$ \\ ${ }^{1}$ Department of Civil and Environmental Engineering, Massachusetts Institute of Technology, Cambridge, \\ MA, USA. \\ ${ }^{2}$ Department of Civil and Environmental Engineering, Tufts University, Medford, MA, USA.
}

\section{Key Points:}

- The extended Purday solution models the transport-controlled dissolution in an evolving fracture.

- The modeling and experimental results show that the overall dissolution rate decreases as the fracture enlarges.

- Channel formation and sidewalls affect fracture morphology and further reduce the dissolution rate. 


\begin{abstract}
Understanding the controlling mechanism and the resulting rate of reactive transport processes is crucial for an accurate prediction of the evolution of the rock-fluid system in many geological processes and engineering applications. In this study, transportcontrolled dissolution in a single fracture was investigated analytically with the development of the extended Purday solution and experimentally with fracture flow tests. The extended Purday solution simulates dissolution in an evolving fracture and extends the validity domain of the Purday solution from a fracture with a uniform aperture to a fracture with aperture heterogeneity in the flow direction. The fracture flow tests include continuous effluent concentration measurements with a novel experimental setup and 3D fracture geometry analysis. The modeling and experimental results agree well and show that the high dissolution rate in the entrance region results in a converging fracture geometry (decreasing aperture in the flow direction). This converging geometry, in turn, reduces the overall dissolution rate in the fracture. The comparison between the modeling and experimental results shows that channel formation and sidewalls affect the morphology of the fracture. The resulting cross-section geometry of the fracture also tends to reduce the overall dissolution rate. This study shows that the extended Purday solution accurately predicts the dissolution rate in an evolving fracture, and that factors, such as channel formation and sidewalls, affect fracture morphology and reduce the overall dissolution rate.
\end{abstract}

\title{
Plain Language Summary
}

Flow and dissolution in underground fractures drive the evolution of the rock-fluid systems. Examples of this can be found in karst formations, enhanced oil production, and $\mathrm{CO}_{2}$ storage. The flow and dissolution change the fracture geometry, which, in turn, reshapes the flow and changes the dissolution rate. This study looked into flow and dissolution in a fracture where the dissolution rate is controlled by the diffusion from the interface to the flowing fluid. The problem is investigated theoretically by developing the extended Purday solution and experimentally using fracture flow tests. The modeling and experimental results agree well and show that the dissolution enlarges the fracture more near the inlet than in the following region, forming a converging fracture geometry. This converging geometry slows down the dissolution in the fracture. The fracture flow tests also show that channels, which are the major flow paths deeply etched in the fracture surface, and the fracture sidewalls affect how the fracture geometry changes and further reduce the overall dissolution rate. The extended Purday solution can be applied to model dissolution in natural fractures or fracture networks. The experimental methods can be used in fracture flow tests to study various geological processes and engineering applications.

\section{Introduction}

Fractures are ubiquitous in the Earth's subsurface (Berkowitz, 2002; Pyrak-Nolte et al., 2015; Deng \& Spycher, 2019). They provide dominant flow pathways because of their high permeability, and thus typically control fluid migration and solute transport in the fractured rock-fluid system (Detwiler, 2008). Reactive transport processes in fractures are important components of many geological processes and engineering applications such as karstification (Dreybrodt, 2012), dam stability (Cooper \& Gutiérrez, 2013), oil reservoir stimulation (Barron et al., 1962) and $\mathrm{CO}_{2}$ sequestration (Fitts \& Peters, 2013). The flow and reaction conditions determine the evolution of the fracture, such as fracture sealing (Elkhoury et al., 2015), fracture opening (Detwiler et al., 2003), and channel formation (Deng \& Peters, 2019). To accurately predict the evolution of the rockfluid system, the controlling mechanisms and the resulting rates of reaction and transport in a fracture need to be well understood. 
Two processes determine the dissolution rate of a solid in an aqueous solution: (a) the chemical reaction at the surface, (b) mass transport of the dissociated ions away from the surface (Jeschke et al., 2001). The slower process of the two controls the dissolution rate, and categorizes the dissolution as: reaction-controlled, transport-controlled and mixed reaction/transport-controlled. Dissolution in subsurface rock-fluid systems, such as evaporitewater (W. Li \& Einstein, 2017), and sandstone-acid (Fredd \& Fogler, 1998), are usually considered to be transport-controlled. The dissolution mass flux $\left(q_{w}\right)$ of transport-controlled dissolution in a conduit takes the general form:

$$
\begin{aligned}
q_{w} & =k_{t}\left(C_{e q}-C_{b}\right) ; \\
k_{t} & =\frac{D \cdot S_{h}}{L_{c}}
\end{aligned}
$$

where $k_{t}$ is the transport-controlled dissolution rate coefficient; $C_{e q}$ is the equilibrium concentration of the solute with the unit of mass per unit volume; $C_{b}$ is the bulk concentration (defined in Section 2); $D$ is the diffusion coefficient; $S_{h}$ is the Sherwood number; and $L_{c}$ is the characteristic length of the conduit (Lasaga, 1998; Brantley et al., n.d.; Budek \& Szymczak, 2012). The Sherwood number $\left(S_{h}\right)$ is the dimensionless form of $k_{t}$, representing the ratio of mass transfer to diffusion rate (Bird et al., 2015; Lienhard, 2011). The Purday solution (Purday, 1949), which models the transport-controlled dissolution in laminar flow in a fracture with a uniform aperture, has been used to calcuate the Sherwood number (MacQuarrie \& Mayer, 2005; Detwiler \& Rajaram, 2007; L. Li et al., 2008; Szymczak \& Ladd, 2012; Kaufmann et al., 2014; Noiriel \& Deng, 2018; Starchenko \& Ladd, 2018; Molins et al., 2019). The Purday solution produces a Sherwood number, which is high in the entrance region and asymptotically approaches 7.54 in the following region (Bird et al., 2015; Lienhard, 2011). By assuming that the fracture aperture is piecewise constant, numerical models incorporating the Purday solution were developed to simulate flow and dissolution in rough fractures and fracture networks with single- or multicomponent reactions (Detwiler \& Rajaram, 2007; Szymczak \& Ladd, 2011; Budek \& Szymczak, 2012; Szymczak \& Ladd, 2012; Wen et al., 2016; Deng \& Spycher, 2019). These theoretical studies are often combined with fracture flow tests to investigate the effect of flow rate, surface roughness, rock heterogeneity, multiphase flow and fluid-rock reactivity on the fracture permeability change, channel formation, precipitation and fracture sealing (Durham et al., 2001; Dobson et al., 2001; Polak et al., 2004; J. Liu et al., 2005; Singurindy \& Berkowitz, 2004, 2005; Detwiler, 2010; Deng et al., 2013, 2018; Walsh et al., 2013; Ellis et al., 2013; Jung et al., 2014; Cao et al., 2015, 2016; Brunet et al., 2016; Jones \& Detwiler, 2016).

However, reactive transport models usually incorporate the Purday solution by using the asymptotic value (7.54) of the Sherwood number to calculate the transport-controlled dissolution rate. As will be shown in Section 2, neglecting the high Sherwood number in the entrance region would result in errors in the calculation of dissolution flux, and thus fracture geometry. This high dissolution rate enlarges the fracture more near the inlet than in the following region, forming a converging fracture geometry and inducing transverse flow $\left(u_{y}\right.$ in Figure 1$)$. This is no longer in the validity domain of the Purday solution and needs to be rigorously modeled analytically. For the combined theoretical and experimental research, few fracture flow tests have effluent chemistry data to study the dissolution rate and to compare with the modeling results regarding the evolution of dissolution rates. In the few studies that provide effluent chemistry, it is measured by sampling the effluent for the effluent chemistry analysis, which yields a limited number of measurements and is susceptible to errors caused by the pressure and temperature change (W. Li et al., 2019a).

In this study, the transport-controlled dissolution in an evolving fracture is investigated analytically and experimentally. The extended Purday solution is developed to explicitly model the entrance region, the converging fracture geometry and the transverse flow velocity (Section 2). To compare with theoretical predictions, fracture flow 
tests are conducted with continuous effluent concentration measurements followed by 3D quantitative fracture geometry analysis (Section 3). In Section 4, the modeling and experimental results are presented. Section 5 involves extensive discussions on how dissolution induced fracture morphology in turn affect the transport-controlled dissolution rates. Section 5 also compares how the overall dissolution rates evolve for transport-controlledand reaction-controlled dissolution in a fracture (with and without channel formation) and in a tube. The implications of these findings for theoretical, laboratory and field studies are then discussed regarding dissolution rates, fracture morphology, and laboratoryfield rate discrepancy.

\section{The Extended Purday Solution}

In this section, the governing equations of the transport-controlled dissolution in a fracture with evolving aperture are derived and solved. This is done by extending the Purday solution. The original Purday solution solves for the temperature of the fluid in laminar flow between two parallel plates with uniform temperature (Purday, 1949; Schenk \& Dumore, 1953; Sellars et al., 1954; Schenk, 1955; Brown, 1960; Schenk \& Han, 1967). This heat transfer problem is analogous to the transport-controlled dissolution in a planar fracture. Since the fracture geometry is altered by dissolution, the Purday solution needs to be extended to account for this evolving fracture geometry.

\subsection{Governing Equations}

For transport-controlled dissolution, the rock-fluid interface is in thermodynamic equilibrium. The concentrations of the ions forming the soluble mineral at the interface are their equilibrium concentrations $\left(C_{e q}\right)$. The transport-controlled dissolution induced by laminar flow in a planar fracture can be modeled using the Purday solution. However, the high dissolution rate near the fracture inlet enlarges the fracture more near the inlet than in the following region, creating two converging fracture surfaces. This converging geometry induces transverse advection, which needs to be accounted for explicitly for an accurate analytical model of the flow and dissolution problem.

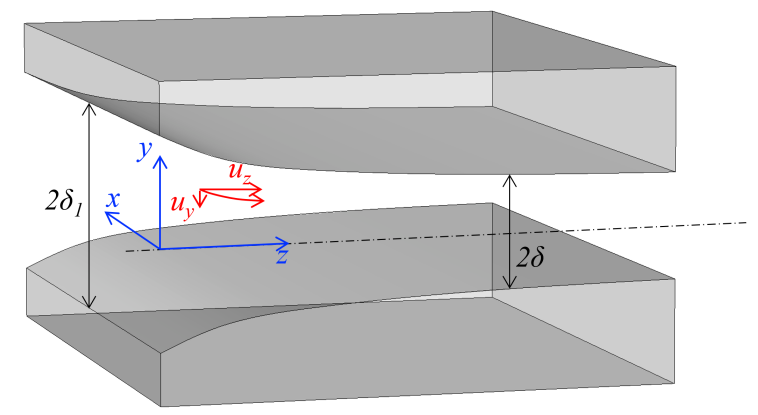

Figure 1. Schematic of the converging fracture geometry after dissolution. A Cartesian coordinate system is assigned to the fracture: $x$ axis in the width direction, $y$ axis in the aperture direction and $z$ axis in the flow direction. The axial velocity $\left(u_{z}\right)$ and transverse velocity $\left(u_{y}\right)$ induced by the fracture geometry are also indicated in red. The fracture is enlarged more near the inlet than in the following region. $2 \delta_{1}$ is the inlet aperture; and $2 \delta$ is the aperture as a function of time $t$ and $z$.

At any time $t$ during the flow and dissolution process, the fracture half aperture $(\delta)$ in the flow direction $(z)$ is assumed to be $\delta=\delta(t, z)$, with the inlet half aperture 
$\delta_{1}$. The physical process is assumed to be the same along the $x$ direction, so the problem can be effectively modeled on the $y-z$ plane (Figure 1 ). The Cartesian coordinates, the aperture $(2 \delta)$, and the velocities $\left(u_{y}, u_{z}\right)$ are shown in Figure 1 . The mass conservation equation for the solute in the flowing fluid can be expressed as:

$$
\frac{\partial C}{\partial t}=-u_{z} \cdot \frac{\partial C}{\partial z}-u_{y} \cdot \frac{\partial C}{\partial y}+D \frac{\partial^{2} C}{\partial z^{2}}+D \frac{\partial^{2} C}{\partial y^{2}}
$$

with the boundary conditions being:

$$
\begin{aligned}
\left.\frac{\partial C}{\partial y}\right|_{y=0} & =0 \quad \text { (symmetric boundary condition); } \\
\left.C\right|_{y=\delta} & =C_{e q} \quad \text { (thermodynamic equilibrium at the solid-fluid interface); } \\
\left.C\right|_{z=0} & =0 \quad \text { (concentration of dissolved rock at inflow); }
\end{aligned}
$$

where $C=C(t, y, z)$ is the concentration of the solute, $D$ is the diffusivity of the solute in the fluid; $u_{z}$ and $u_{y}$ are the axial and transverse flow velocities; $C_{e q}$ is the equilibrium concentration of the solute.

The fully developed laminar flow in a fracture with gradually changing aperture can be expressed as:

$$
\begin{aligned}
& u_{z}(y, z)=\frac{3}{2} \bar{u}_{z 1} \cdot \frac{\delta_{1}}{\delta} \cdot\left(1-\frac{y^{2}}{\delta^{2}}\right), \\
& u_{y}(y, z)=\frac{3}{2} \bar{u}_{z 1} \cdot \frac{\delta_{1}}{\delta} \cdot\left(1-\frac{y^{2}}{\delta^{2}}\right) \cdot \frac{\partial \delta}{\partial z} \cdot \frac{y}{\delta},
\end{aligned}
$$

where $\bar{u}_{z 1}$ is the average flow velocity at the inlet (Lee \& Zerkle, 1969). By assuming that the flow rate in the fracture is $Q$ and that the width of the fracture is $w, \bar{u}_{z 1}$ can be calculated as: $\bar{u}_{z 1}=\frac{Q}{w \cdot 2 \delta_{1}}$.

As discussed by W. Li and Einstein (2017), the hydraulic entrance region is much shorter than the mass transport entrance region for most underground rock-fluid systems. It is thus reasonable to use the fully developed velocity profile (Equations (4)) in the mass conservation equation (Equation (2)). The mass conservation equations (Equations (2) and (4)) describe the transport-controlled dissolution in a prescribed geometry at time $t, \delta=\delta(t, z)$. The Purday solution solves a special case of this mass conservation when $\delta$ is a constant and there is no transverse advection.

The evolution of the fracture aperture can be calculated based on the mass conservation of the soluble rock:

$$
\frac{\partial \delta}{\partial t}=-\left.\frac{1}{\rho_{r}} \cdot D \frac{\partial C}{\partial y}\right|_{y=\delta}
$$

where $\rho_{r}$ is the density of the rock. Assuming the initial half aperture of the fracture is $\delta_{0}$ everywhere in the fracture, the initial condition for Equation (5) can be expressed as:

$$
\left.\delta\right|_{t=0}=\delta_{0}
$$

\subsection{Analytical Solution}

Equations (2)-(6) are the governing equations for the solute concentration in the fracture $C(t, y, z)$ and the evolving fracture geometry $\delta(t, z)$. A closed-form analytical solution for the solute concentration is obtained by using quasi-steady state approximation and neglecting the axial ( $z$ direction) diffusion term, as presented in detail in Appendix A. By using dimensionless coordinates $(\eta, \xi)$, Equation (2) is transformed into 
the same form as the governing equation of the Purday solution:

$$
\begin{aligned}
\frac{3}{8}\left(1-\eta^{2}\right) \cdot \frac{\partial \theta}{\partial \xi} & =\frac{\partial^{2} \theta}{\partial \eta^{2}} \\
\left.\theta\right|_{\xi=0} & =1 \\
\left.\theta\right|_{\eta=1} & =0 \\
\left.\frac{\partial \theta}{\partial \eta}\right|_{\eta=0} & =0
\end{aligned}
$$

Therefore, the Purday solution can be extended to solve transport-controlled dissolution in a converging fracture. This solution process was developed by by Lee and Zerkle (1969); Özişik et al. (1982) for the heat convection between two converging surfaces with a constant temperature. To the authors' best knowledge, what is presented here is the first time this solution is used for transport-controlled dissolution in a fracture. We hereby refer to this solution as the extended Purday solution.

The Purday solution produces the $2-\mathrm{D}$ concentration profile $(\theta=\theta(\eta, \xi))$, which can be reduced to the $1-\mathrm{D}$ bulk concentration $\left(\theta_{b}(\xi)\right)$ and Sherwood number $\left(S_{h}(\xi)\right)$ :

$$
\begin{gathered}
\theta=\sum_{n=1}^{\infty} \frac{-2 \phi_{n}}{\left.\lambda_{n}\left(\frac{\partial \phi_{n}}{\partial \lambda_{n}}\right)\right|_{\eta=1}} \exp \left(-\frac{8}{3} \lambda_{n}^{2} \xi\right) \\
\theta_{b}(\xi)=\int_{0}^{1} \frac{3}{2} \theta\left(1-\eta^{2}\right) d \eta=\sum_{n=1}^{\infty} \frac{\left.3\left(\frac{\partial \phi_{n}}{\partial \eta}\right)\right|_{\eta=1}}{\left.\lambda_{n}^{3}\left(\frac{\partial \phi_{n}}{\partial \lambda_{n}}\right)\right|_{\eta=1}} \exp \left(-\frac{8}{3} \lambda_{n}^{2} \xi\right), \\
S_{h}(\xi)=-\left.4 \cdot \frac{\partial \theta}{\partial \eta}\right|_{\eta=1} / \theta_{b}=\frac{8}{3} \cdot \frac{\sum_{n=1}^{\infty} \frac{\left.\left(\frac{\partial \phi_{n}}{\partial \eta}\right)\right|_{\eta=1}}{\left.\lambda_{n}\left(\frac{\partial \phi_{n}}{\partial \lambda_{n}}\right)\right|_{\eta=1}} \exp \left(-\frac{8}{3} \lambda_{n}^{2} \xi\right)}{\sum_{n=1}^{\infty} \frac{\left.\left(\frac{\partial \phi_{n}}{\partial \eta}\right)\right|_{\eta=1}}{\left.\lambda_{n}^{3}\left(\frac{\partial \phi_{n}}{\partial \lambda_{n}}\right)\right|_{\eta=1}} \exp \left(-\frac{8}{3} \lambda_{n}^{2} \xi\right)}
\end{gathered}
$$

where $\lambda_{n}$ and $\phi_{n}$ are eigenvalues and eigenfunctions of Equation (7) (Brown, 1960). The bulk concentration is the flux-weighted average concentration, which represents the amount of solute carried by the flow. Also, if the effluent of the flow is sampled for concentration measurement, this measured concentration is the bulk concentration. The normalized bulk concentration $\left(\frac{C_{b}}{C_{e q}}\right)$ and Sherwood number can be plotted with respect to the dimensionless axial coordinate $(\eta)$ of the fracture (Figure 2). For comparison, the dimensionless bulk concentration and the Sherwood number for a tapered tube based on the extended Graetz solution (W. Li \& Einstein, 2017) are also plotted. The two analytical solutions both show that the Sherwood numbers are high in the entrance region then approach their asymptotic values 7.54 for a fracture and 3.66 for a tube, respectively. The dimensionless length of the entrance region is around 0.1 , in which about $60 \%$ of the concentration change occurs.

To show how neglecting the entrance region affects the predicted bulk concentration, the prediction using a constant Sherwood number (7.54) is compared with that of the extended Purday solution in Figure 2. The green dashed curve shows that the bulk concentration is underestimated especially in the entrance region. This will result in larger errors in the long-term prediction of fracture geometry, because fracture geometry is calculated by time integration, as will be shown in Section 4. This analytical solution shows that the entrance region should not be neglected when modeling the transport-controlled dissolution in a fracture or a tube.

When using the extended Purday solution, the fitted approximation listed by Shah and London (1978) can be used to calculate the Sherwood number and bulk concentration in the conduit. Based on the quasi-steady state approximation, the concentration 


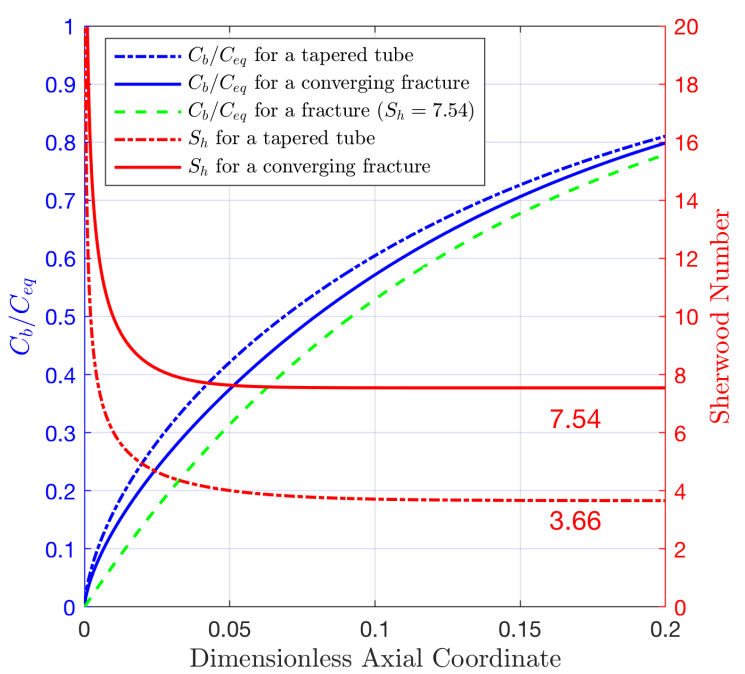

Figure 2. The normalized bulk concentrations and the Sherwood numbers are plotted based on the extended Graetz solution for a tapered tube (a tube with decreasing radius in the flow direction) and the extended Purday solution for a converging fracture (a fracture with decreasing aperture in the flow direction). The normalized bulk concentration calculated using a constant Sherwood number (7.54) is also plotted to compare.

obtained by the extended Purday solution can be used to calculate the rate of change for the fracture geometry (Equation (5)). The updated fracture geometry is then used in the extended Purday solution for the quasi-steady state concentration of the next time step. We can use this scheme to model the evolution of concentration and fracture geometry. The modeling results will be compared with the results of the fracture flow tests in Section 4.

\section{Fracture Flow Tests}

The fracture flow tests were designed to study the evolution of the overall dissolution rate and the change of fracture geometry, and to compare these with the predictions of the extended Purday solution. A novel experimental setup, the effluent chemistry monitoring system (ECMS, detailed in Section 3.2), is used to continuously measure the effluent concentration and study the overall dissolution rate. The X-ray CT scan is used to measure the fracture geometries before and after the flow tests. Topological and morphological algorithms were developed to quantitatively interpret the fracture geometry in $3-\mathrm{D}$.

\subsection{Specimen Preparation}

Gypsum was used as the soluble rock since the dissolution of gypsum is generally transport-controlled (S.-T. Liu \& Nancollas, 1971). The dissolution of gypsum is relevant in causing the formation of karst caverns, increasing the permeability of granular zones and enlarging fissures, and attacking cement. In addition, the gypsum-water system can be used as an analogue to experimentally modeling the dissolution of other rockfluid systems (Daccord, 1987; W. Li et al., 2019a). The gypsum dissolution reaction is 
described in detail by Dreybrodt (2012). Laboratory cast gypsum was used for its consistency and workability.

A mold was designed to cast the fracture in the gypsum specimen. A rubber band with a uniform thickness and width was used as the mold for the fracture. Two end caps each with a slot to hold the rubber band were used when casting the gypsum specimen. After the specimen is cured, the rubber band is removed and a thin rectangular duct is left in the specimen as the planar fracture, as shown in Figure 3(b). The specimen is trimmed and polished at the ends to around $8.50 \mathrm{~cm}$ length. The planar fracture has a thin rectangular cross section of $1.150 \mathrm{~cm}$ width and $0.034 \mathrm{~cm}$ aperture on average according to the CT data analysis (Sections 3.3 and 4.1). This specimen preparation method produces specimens with consistent geometry and material properties (W. Li et al., 2019a).

\subsection{Experimental Setup}

The triaxial system used for the gypsum core flood test (W. Li et al., 2019a) was used for the fracture flow tests. The triaxial system controls and monitors the injection rate, confining stress, axial stress and back pressure (outlet pressure). It monitors the inlet pressure, effluent temperature and effluent concentration. A schematic of the fracture flow test is shown in Figure 3(a), with a detailed 3-D model of the specimen and the Cartesian coordinates (Figure 3(b)).

The ECMS is integrated into the top end cap of the triaxial system, where the effluent flows through. The ECMS is based on the four-probe electric conductivity measurement and is calibrated to relate the measured electric conductivity to the mass of dissolved gypsum in a unit volume of solution. Since the gypsum-water system only has one soluble component, this measured concentration reflects the mole concentration of both the calcium ion and the sulfate ion. During the core flood test, the ECMS measures the concentration and temperature of a small volume $(<0.1 \mathrm{~mL})$ of effluent in the top end cap $\left(V_{m}\right)$. This volume of the effluent is continuously replaced by the newly generated effluent, providing a fast effluent replacement so that the concentration and temperature are updated fast enough for continuous measurement with high time-resolution. The ECMS avoids the time-consuming effluent sampling and analysis processes, and the errors associated with temperature and pressure change during these processes. It is best suited for this single component rock-fluid systems.

Four fracture flow tests were conducted, each with a constant flow rate. The four flow rates were: $5,10,20$ and $40 \mu \mathrm{L} / \mathrm{s}$. Each test was conducted with consistent test processes: mass measurement before test, test assembly, application of confining and axial stress $(200 \mathrm{kPa})$, vacuum saturation, back pressurization $(70 \mathrm{kPa})$, overnight saturation and flowing $500 \mathrm{~mL}$ distilled water. During the flow test, the effluent concentration was continuously measured by the ECMS along with the other parameters such as effluent temperature, inlet pressure, outlet pressure, confining stress, axial stress, and axial displacement. Of these parameters, only the effluent concentration will be presented in Section 4.2. Other parameters such as effluent temperature, outlet pressure, confining stress and axial stress were controlled by the triaxial system to be constant. Due to the high permeability of the fractures, the pressure difference between the inlet and outlet was less than $1 k P a$, which was close to the combined noise level of the two sensors. Therefore it is not presented in this study. After the flow tests, the specimens were dried at $40^{\circ} \mathrm{C}$ for seven days before the mass measurements and $\mathrm{CT}$ scanning.

\subsection{CT Scan and Data Analysis Methods}

In addition to the four specimens after the fracture flow tests, a fifth specimen that was not subject to a flow test was scanned for initial fracture geometry analysis. Given the consistency of the specimen preparation methods and material properties (W. Li et 


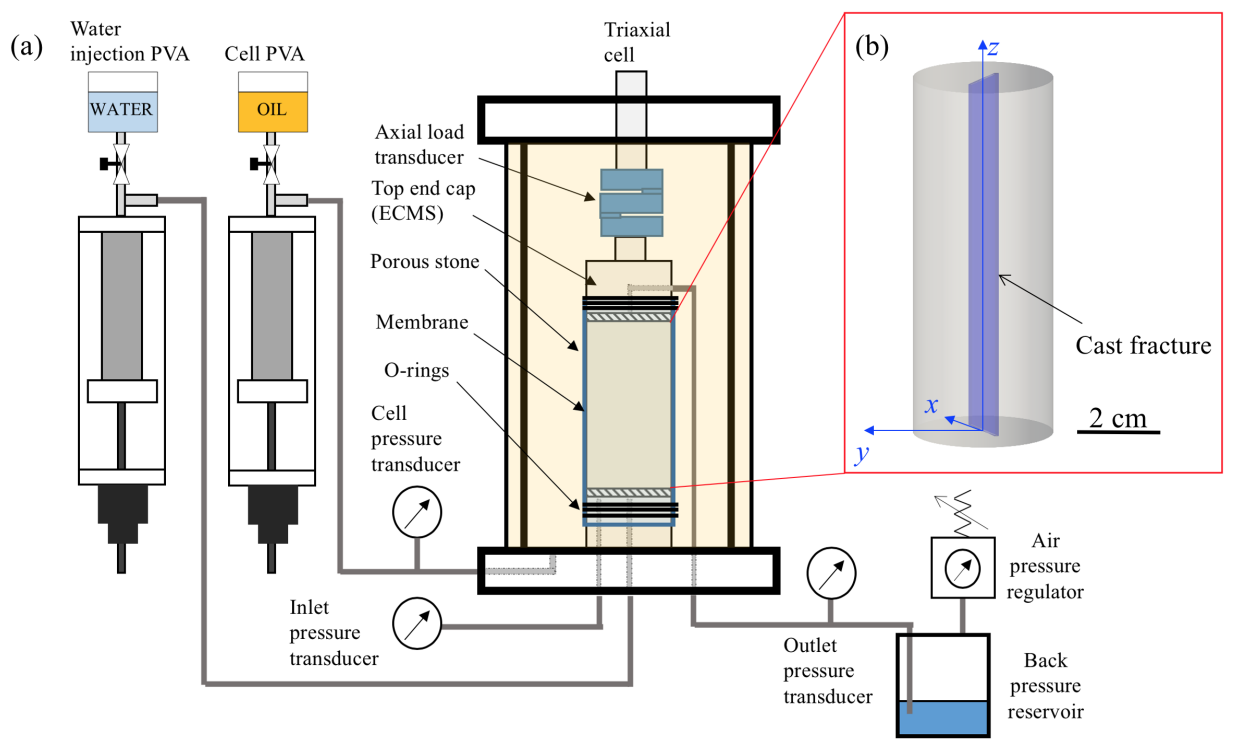

Figure 3. Schematic of the fracture flow test. (a) Triaxial system used for fracture flow tests. The top end cap of the ECMS is shown in the setup. The parts in the setup are not drawn in the same scale. PVA = pressure -volume actuator. (b) The 3-D model of the specimen is drawn to scale with the Cartesian coordinates.

al., 2019a), the fifth specimen was used as a representative for the initial state of the specimens before flow tests. The CT scanning used a $4 \times$ magnification, which resulted in a voxel resolution of $50 \mu \mathrm{m}$. The software Inspect-X (Quiggin, 2011) was used to reconstruct the 3-D model of the specimen. The 3-D model was then exported as image stack of specimen cross sections perpendicular to the flow direction.

The cross section near the inlet of the specimen after the flow test with $Q=5 \mu L / s$ is used here as an example to describe the image processing algorithms. Figure 4(a) shows one image stack (cross section) of the specimen. It is a greyscale image, with higher brightness representing higher density and lower brightness representing lower density. Each image in the image stack is first rotated to align the fracture to the horizontal width $(x)$ direction, then cropped to the area of interest for faster processing (Figure 4(b)). Since the specimen material is almost pure gypsum, image segmentation (Figure 4(c)) for the solid phase and air phase is relatively straightforward (Deng et al., 2016). After the image segmentation, the fracture on each cross section as the biggest "connected component" (Russ, 2016) is isolated and saved as a 3-D binary matrix for fracture geometry analysis.

\subsubsection{Fracture width}

In the Cartesian coordinate system (Figure 4(d)), the fracture width direction is in the $x$ direction. The fracture width field $(w(y, z))$ can be calculated by totaling the number of white voxels along the $x$ direction $N_{v x}(y, z)$ and convert this number to width:

$$
w(y, z)=N_{v x}(z) \times 50 \mu m .
$$

The maximum width shown in Figure 4(e) is referred to as the width of the fracture. This is calculated by taking the maximum width in each cross section. 

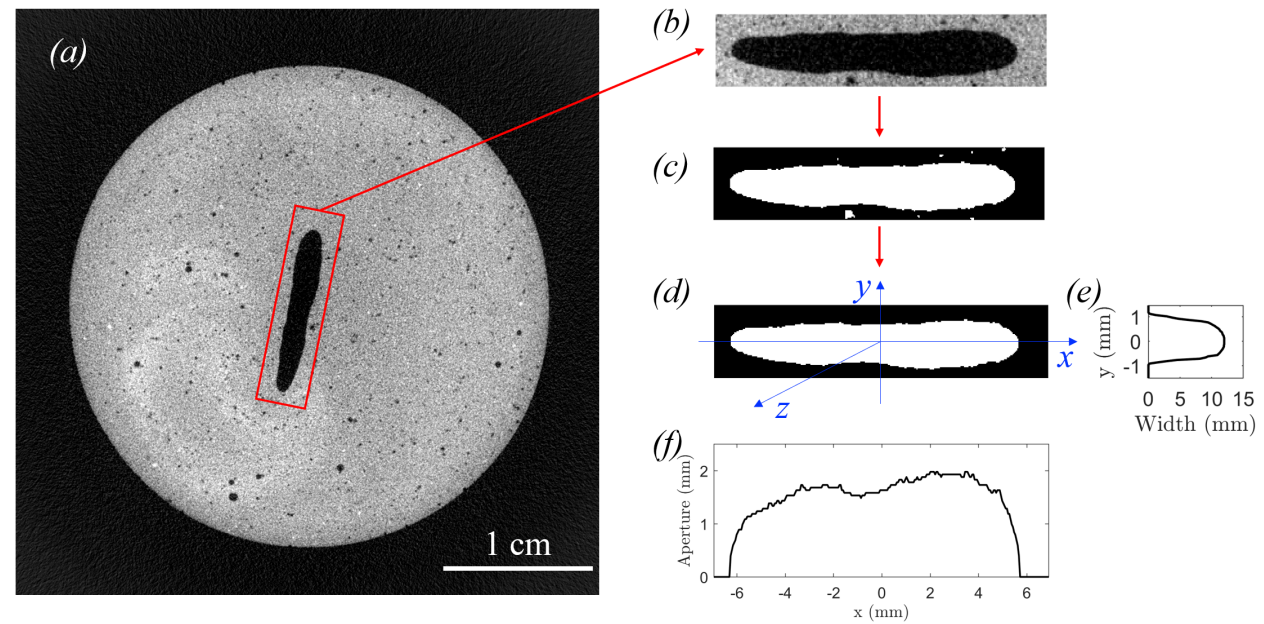

Figure 4. CT scan data processing. (a) Image stack of horizontal cross sections of the specimen. (b) Rotated and cropped cross section. (c) Inverted binary image of the cross sections with 1 (white) to represent the void space. (d) Fracture is isolated for geometric analysis in the Cartesian coordinate system consistent with Figures 1 and 3(b). (e) Fracture width calculated based on Equation (9). (f) Fracture aperture based on Equation (11).

$$
w(z)=\left.\max (w(y, z))\right|_{y} .
$$

The widths of the fractures before and after the flow test are presented in Section 4.

\subsubsection{Fracture aperture}

Similar to the algorithms to calculate the width, the fracture aperture field can be calculated by totaling the number of white voxels in the $y$ direction $N_{v y}$ and covert this number to aperture:

$$
2 \delta(x, z)=N_{v y}(x, z) \times 50 \mu m,
$$

where $\delta$ is the half aperture as used in Section 2. The fracture aperture calculated using this method is shown in Figure 4(f). Since the fracture aperture varies in the width direction $(x)$, the average fracture aperture is calculated as the fracture area divided by the fracture width. The fracture area $\left(A_{f}(z)\right)$ in each cross section is the number of all the white voxels in this cross section $N_{A f}(z)$ times the area of each voxel:

$$
A_{f}(z)=N_{A f}(z) \times 50 \times 50 \mu m^{2} .
$$

The average fracture aperture is then calculated as:

$$
2 \bar{\delta}(z)=\frac{A_{f}(z)}{w(z)} .
$$

The fracture aperture field $2 \delta(x, z)$ and average fracture aperture $2 \bar{\delta}(z)$ before and after the flow tests are presented in Section 4 and compared with the predictions of the extended Purday solution. 


\subsection{Summary of Experimental Parameters}

The experimental parameters are summarized in Table 1. The material properties: $C_{e q}, D, k_{r}, \rho_{r}$ are taken from the studies by Jeschke et al. (2001) and W. Li et al. (2019a). The width $(w)$ and aperture $(2 \delta)$ of a representative initial fracture were measured using CT scanning as discussed in Section 3.3. The specimen length was measured directly and is assumed to be the fracture length $\left(L_{f}\right)$.

Table 1. Experimental parameters used in the fracture flow tests

\begin{tabular}{|c|c|c|c|}
\hline Symbol & Value & Unit & Variable \\
\hline$\overline{C_{e q}}$ & $2.6 \times 10^{-3}$ & $\mathrm{~g} / \mathrm{cm}^{3}$ & Solubility of gypsum in distilled water \\
\hline$D$ & $9.0 \times 10^{-6}$ & $\mathrm{~cm}^{2} / \mathrm{s}$ & Diffusion coefficient \\
\hline$k_{r}$ & $7.1 \times 10^{-3}$ & $\mathrm{~cm} / \mathrm{s}$ & Reaction-controlled dissolution rate coefficient \\
\hline$\rho_{r}$ & 1.22 & $\mathrm{~g} / \mathrm{cm}^{3}$ & Gypsum density \\
\hline$w$ & 1.150 & $\mathrm{~cm}$ & Average initial fracture width (representative) \\
\hline $2 \delta$ & 0.034 & $\mathrm{~cm}$ & Average initial fracture aperture (representative) \\
\hline$L_{f}$ & $8.66,8.41,8.63,8.58$ & $\mathrm{~cm}$ & Fracture lengths \\
\hline$Q$ & $5,10,20,40$ & $\mu L / s$ & Injection flow rates \\
\hline
\end{tabular}

With the above experimental parameters, the controlling mechanism of the transport and dissolution can be determined using dimensional analysis. The Péclet number $\left(P_{e}\right)$ and the second Damköhler number $\left(D_{a I I}\right)$ defined by Deng and Spycher (2019) are used in this dimensional analysis. The Péclet number for the fracture is defined as:

$$
P_{e}=\frac{\bar{u}_{z} \cdot 4 \delta}{D}
$$

where $\bar{u}_{z}$ is the average flow velocity, $\bar{u}_{z}=\frac{Q}{2 \delta \cdot w}$. With the above experimental parameters, the Péclet number is in the range of $(1 \sim 8) \times 10^{3}$. This shows that the axial advection is much faster than diffusion, and that the axial diffusion term can be neglected, as discussed in Section 2. The second Damköhler number $\left(D_{a I I}\right)$ for the fracture is:

$$
D_{a I I}=\frac{k_{r} \cdot 2 \delta}{D}
$$

With the experimental parameters listed in Table 1, the second Damköhler number is 54 for all four cases. This indicates that the reaction occurs faster than the diffusion and that the dissolution is indeed transport-controlled. The dimensional analysis shows that the designed experiments are in the validity domain of the extended Purday solution and that the modeling and experimental results can be compared.

\section{Modeling and Experimental Results}

This section compares the modeling and experimental results. The extended Purday solution, with experimental parameters listed in Table 1, is used to simulate the evolution of the fracture geometry and effluent concentration. The 3-D fracture geometry and the continuous effluent concentrations measured in the fracture flow tests are compared with the predictions of the extended Purday solution. 


\subsection{Fracture Geometry}

\subsubsection{Fracture aperture field}

The fracture aperture field $(2 \delta(x, z))$ based on the CT scan (Section 3.3) of the initial fracture and of the fractures after the flow tests with different flow rates are plotted in Figure 5(a-e). The fracture length and width are drawn to scale as indicated with the scale bar. The fracture aperture is color mapped as indicated with the color bar. The flow direction is in the $z$ direction, as indicated with the arrow.

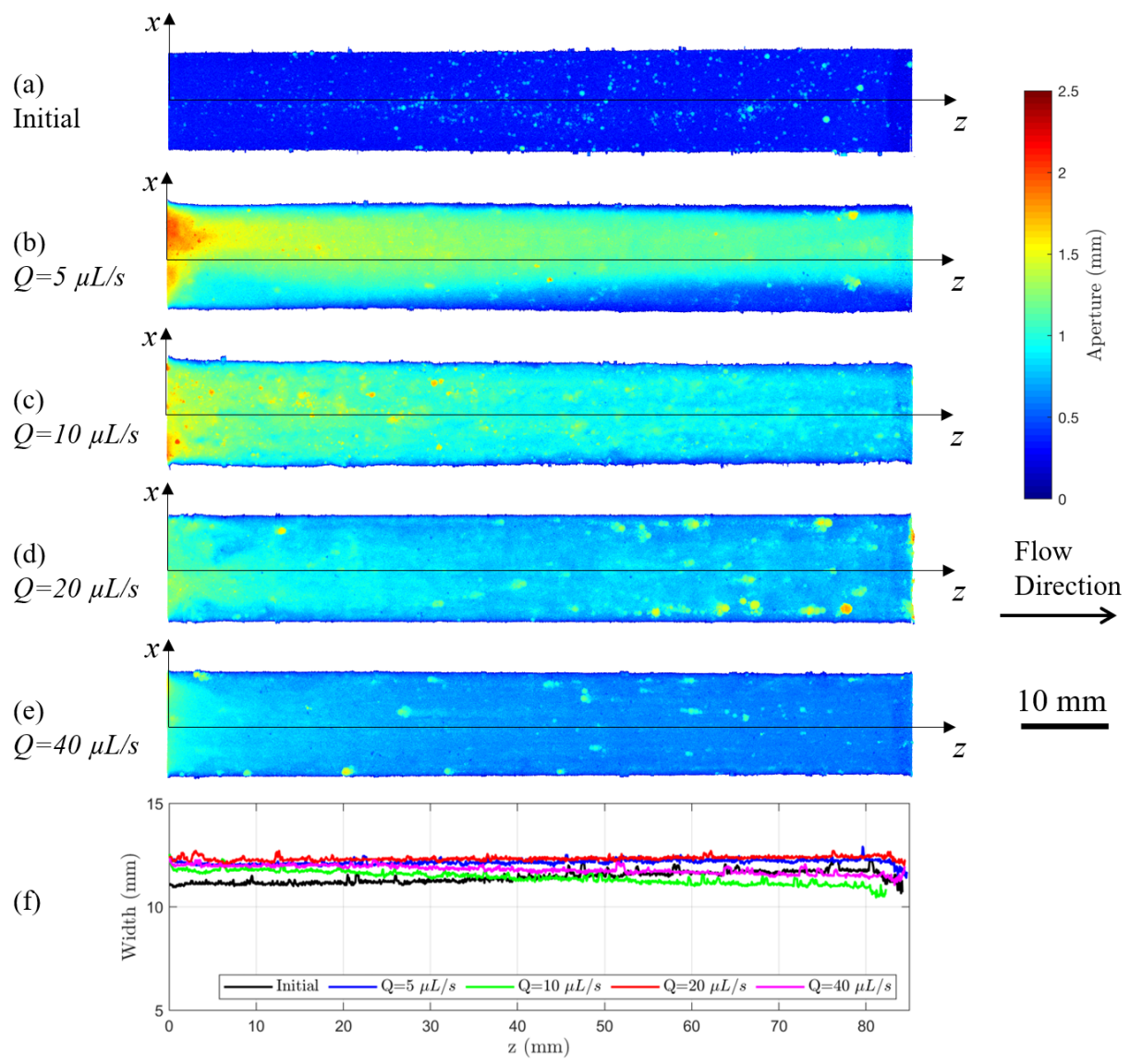

Figure 5. Fracture aperture and fracture width. (a) Initial fracture aperture based on the representative specimen. (b-e) Fracture aperture after flow tests with different flow rates. (f) Initial fracture width and fracture widths after the flow tests. Due to the low transport-controlled dissolution rate near the sidewalls, the fracture widths do not change much (see Section 5.2.2).

The initial fracture aperture is uniform, except for some larger aperture spots. These spots are the result of the air bubbles during the casting process. To characterize these spots, the fracture area that has an aperture larger than twice the average aperture $(0.034 \mathrm{~cm})$ is investigated. It shows that these spots only take $0.91 \%$ of the whole aperture field. Therefore, the initial fracture aperture can be treated as uniform.

After the flow tests, the fracture aperture fields are not uniform in either the flow direction $(z)$ or the width direction $(x)$. In the flow direction $(z)$, the fractures were enlarged more near the inlet than in the following region, as indicated with warmer colors in Figure 5. This is due to the high dissolution rate as indicated by the Sherwood 
number and high thermodynamic driving force $\left(C_{e q}-C_{b}\right)$. In the width direction $(x)$, the fracture aperture was enlarged less at the edges of the fractures $(x= \pm w / 2)$ than the inner part of the fracture. This results in an elliptical cross section, which is also observed in Figure 4. The reason for the aperture heterogeneity in the width direction will be given in Section 5.2.2. In the test with the lowest flow rate $(Q=5 \mu L / s)$, a channel began to form with greater aperture than the rest of the fracture, as indicated with the red near the inlet and green near the outlet. The detailed discussion on channel formation will be presented in Section 5.2.1.

\subsubsection{Fracture width}

The fracture widths are calculated based on the algorithms described in Section 3.3 and plotted in Figure 5(f). The initial fracture width measured from the representative specimen is around $1.15 \mathrm{~cm}$. The widths of the four fractures after the flow tests are also around $1.15 \mathrm{~cm}$, as shown in Figure 5. Hence, the fracture width did not change much during the flow test, as will be discussed later in Section 5.2.2. The difference between the fractures is within $13 \%$ of the average width and is likely to be the result of experimental variations during specimen preparation.

\subsubsection{Average fracture aperture}

Figure 6 shows the experimental results (solid curves) calculated based on the algorithms described in Section 3.3. These are compared to the modeling results using the extended Purday solution (dashed curves) and those using a constant Sherwood number (7.54, dashdotted curves) with the experimental parameters listed in Table 1.

The experimental results show that the average fracture apertures increased to two or three times of the initial aperture. Higher flow rates result in smaller fracture apertures. The fractures all have much larger aperture near the inlet than the rest, forming a converging fracture geometry. The fracture apertures are better captured with the extended Purday solution than using a constant Sherwood number. This is because the extended Purday solution accounts for the effect of the entrance region and the converging fracture geometry. In contrast, when using a constant Sherwood number, the modeling results underestimate the increase of the fracture aperture near the inlet. For the case with $Q=5 \mu L / s$, the modeling results deviate from the experimental results, because of the distinct channel formation. The effect of channel formation will be discussed in Section 5.2.1.

\subsection{Effluent Concentration}

Effluent concentration reflects the overall dissolution rate, $R_{\text {overall }},\left(R_{\text {overall }}=Q \times\right.$ $\left.\left(C_{e f f}-C_{i n}\right)\right)$ and the evolution of the rock-fluid system during flow tests (Noiriel et al., 2009). The continuous effluent concentration data measured by the ECMS in the fracture flow tests are shown in Figure 6 . The effluent concentrations predicted by the extended Purday solution and the model using constant Sherwood number (7.54) are also plotted in Figure 6 for comparison.

Because of the high time-resolution of the ECMS, the initial transient states of the dissolution during the flow tests were captured, which are reflected by the sharp changes in the beginning. During these transient states, the newly injected fluid pushed out the fluid that was initially in the fracture during overnight saturation and started to establish the quasi-steady state between the new fluid and the rock. The initial fracture volume $\left(w \times 2 \delta \times L_{f}=0.33 \mathrm{~mL}\right)$ is small comparing to the injected volume $(500 \mathrm{~mL})$. Therefore, the initial transient state is relatively short, as shown in Figure 6. Then, the effluent concentrations slowly decrease, which indicates a decreasing overall dissolution rate. Among the four tests, higher flow rates result in lower effluent concentration. 

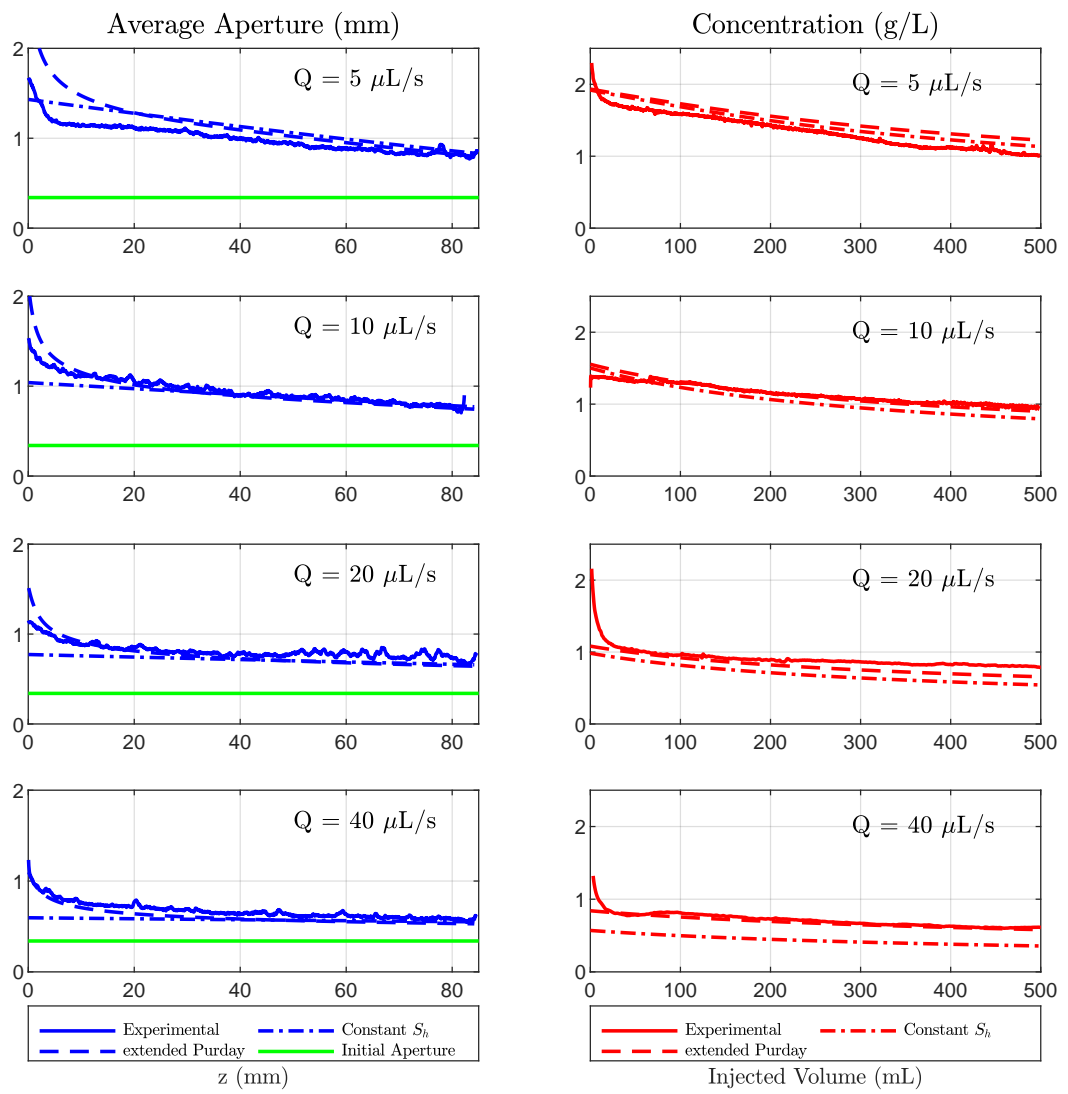

Figure 6. Comparison among experimental results (solid lines), modeling results with the extended Purday solution (dashed lines) and modeling results with a constant Sherwood number (7.54) (dashdotted lines). The average fracture apertures are plotted on the left. In the experiments, the fractures enlarged more near the inlet than in the following region. The modeling results with extended Purday solution capture this feature quite well. The effluent concentrations are plotted on the right. Except for the case with distinct channel formation $(Q=5 \mu L / s)$, the Purday solution models the evolution of the effluent concentration quite accurately, while the model with constant Sherwood number underestimates the effluent concentrations.

Since the extended Purday solution only accounts for the quasi-steady state dissolution, the initial transient state is not captured. Figure 6 shows that, except for the relatively short initial transient state, the magnitude and the decreasing trend of the effluent concentrations for the four tests were better predicted by the extended Purday solution than the model using constant Sherwood number (7.54). An explanation for this decreasing trend will be provided in Section 5.1. Except for the case with $Q=5 \mu L / s$, where a channel began to form in the fracture, the predicted effluent concentrations agree with test results. For the case with $Q=5 \mu L / s$, the effluent concentration was overestimated due to the fact that a channel formed in the fracture and most of the flow converged in the channel.

\section{Discussion}

The analytical model and the fracture flow tests both use a fracture with a uniform aperture as its initial geometry to study the evolution of the fracture geometry and 
overall dissolution rates. This section discusses how the fracture evolves from a thin rectangular duct to a fracture with aperture heterogeneity in both the flow and width directions, and how this fracture morphology, in turn, affects the transport-controlled dissolution rate. This discussion will not only provide explanations for the differences between the modeling and experimental results in this study but also extend beyond transportcontrolled dissolution to the comparison with reaction-controlled dissolution. Implications for laboratory and field studies of reactive transport processes are also provided based on these discussions.

\subsection{Fracture aperture heterogeneity in the flow direction}

Both the modeling and experimental results show a decreasing effluent concentration during the flow test with constant flow rate. This indicates that the overall dissolution rate decreases as the fracture aperture increases. The behavior of the overall dissolution rate is different from that of transport-controlled dissolution in a tube (W. Li \& Einstein, 2017). This section provides a theoretical explanation for the decreasing overall dissolution rate and how the extended Purday solution differs from the extended Graetz solution (W. Li \& Einstein, 2017).

In the extended Graetz solution, the dimensionless axial coordinate for the tapered tube $\left(Z_{t}\right)$ is defined as:

$$
Z_{t}=\frac{\pi D}{2 Q} \cdot z
$$

Equation (16) shows that the dimensionless axial coordinate $\left(Z_{t}\right)$ does not depend on the tube geometry but on the flow rate. As the reactive transport process changes the tube geometry, the dimensionless axial coordinate will not change unless the flow rate changes. The effluent concentration, as a function of the dimensionless axial coordinate, will be constant for a constant flow rate, despite the evolution of the tube geometry. This has been numerically and experimentally validated by W. Li and Einstein (2017); W. Li et al. (2018).

In the extended Purday solution, the dimensionless axial coordinate is defined as:

$$
\xi=\int_{0}^{\frac{D z w}{2 Q} \cdot \frac{1}{\delta_{1}}} \frac{\delta_{1}}{\delta} d Z_{f}
$$

The dimensionless axial coordinate $(\xi)$ depends on not only the flow rate, but also the current fracture aperture profile in the flow direction $(\delta(t, z))$. As the geometry of the fracture evolves during dissolution, the dimensionless coordinate changes even when the flow rate is constant. When the fracture aperture enlarges under constant flow rate, the current fracture aperture is larger than the initial fracture aperture, $\delta_{0}<\delta(t, z),(0<$

$t)$. This leads to $\frac{\delta_{1}(t)}{\delta(t, z)}<\frac{\delta_{1}(t)}{\delta_{0}}$. The dimensionless coordinate $\xi(t)$ at time $t(0<t)$ has the relation:

$$
\xi(t)=\int_{0}^{\frac{D z w}{2 Q} \cdot \frac{1}{\delta_{1}(t)}} \frac{\delta_{1}(t)}{\delta(t, z)} d z<\int_{0}^{\frac{D z w}{2 Q} \cdot \frac{1}{\delta_{1}(t)}} \frac{\delta_{1}(t)}{\delta_{0}} d z=\frac{D z w}{2 Q} \cdot \frac{1}{\delta_{0}}=\left.\xi\right|_{t=0}
$$

The dimensionless axial coordinate $\left(\xi_{t}\right)$ at $t>0$ is then less than the initial dimensionless axial coordinate $\left(\left.\xi\right|_{t=0}\right)$. The effluent concentration, as a function of the dimensionless axial coordinate, decreases with the decreasing dimensionless axial coordinate. This leads to the prediction that as the fracture enlarges due to dissolution under constant flow rate, the effluent concentration is less than the initial quasi-steady state concentration, as shown in Figure 6. 
The explanation for this difference can also be given using scaling analysis. The concentration of the dissolved mass depends on the rate of axial advection and transverse diffusion. Faster axial advection or slower transverse diffusion result in lower concentration. The rate of axial advection is proportional to $\bar{u}_{z} / L$, while the rate of transverse diffusion is proportional to $D / R^{2}$, where $L$ and $R$ are the axial and transverse characteristic lengths. When a tube enlarges due to dissolution, the average axial velocity $\bar{u}_{z}=Q /\left(\pi R^{2}\right)$ scales the same as the transverse diffusion $\left(D / R^{2}\right)$ to the radius $R$. Therefore, the concentration remains constant. When a fracture enlarges due to dissolution, the width does not change (Section 5.2.2). The average axial velocity $\bar{u}_{z}=Q /(2 \delta w)$ does not reduce as much as the transverse diffusion $\left(D / \delta^{2}\right)$. Hence, the concentration decreases.

is proportional to $1 / \delta$, while the transverse diffusion is proportional to $1 / \delta^{2}$.

The axial advection is slowed down less than the transverse diffusion, resulting in a lower concentration.

\subsection{Fracture aperture heterogeneity in the fracture width direction}

Since the extended Purday solution accounts for the fracture aperture heterogeneity in the flow direction but not for that in the width direction, the differences between the modeling and experimental results are expected to be a result of the fracture aperture heterogeneity in the width direction. This section discusses how the aperture heterogeneity in the width direction, such as the channel formation, the sidewalls and the fracture cross-section geometry, affect the dissolution rate.

\subsubsection{Channels}

Channels are major flow paths deeply etched in the fracture surface that formed due to the dissolution front instability (Szymczak \& Ladd, 2012). Extensive studies (Szymczak \& Ladd, 2009, 2012; Upadhyay et al., 2015; Osselin et al., 2016; Dreybrodt \& Gabrovšek, 2019; Grodzki \& Szymczak, 2019) have shown that the dissolution front is not stable for a wide range of flow and reaction conditions. The types of channels formed under different conditions have also been investigated in many studies (Dijk et al., 2002; Detwiler \& Rajaram, 2007; Detwiler, 2008; Szymczak \& Ladd, 2009; Deng et al., 2013; Upadhyay et al., 2015; Osselin et al., 2016; Noiriel \& Deng, 2018; Deng \& Peters, 2019). After channel formation, most of the flow and dissolution occur in the channels. The channel developed in the flow test with $Q=5 \mu L / s$ in Figure 5 is in the initial stage where the aperture contrast to the rest of the fracture is not yet well pronounced. If the tests were to continue for a longer time, the aperture contrast between the channel and the rest of the fracture would be even higher. Nevertheless, because of the channel formation, the measured effluent concentration deviates from the prediction of the extended Purday solution (Figure 6).

\subsubsection{Sidewalls}

The Purday solution is often used to model the flow and dissolution in a single fracture, assuming that the fracture is wide enough to neglect the sidewalls. However, for fracture flow tests, the fractures are bounded by the sidewalls at $x= \pm w / 2$ in the width direction. The errors caused by the sidewalls are small when calculating laminar flow and dissolution with the initial fracture geometry (Shah \& London, 1978). However, the error increases as the fracture geometry evolves due to dissolution.

Valueva and Purdin (2016) simulated the laminar flow induced heat convection in rectangular ducts and calculated the local Nusselt number on the duct surfaces. Since the Nusselt number of heat transfer is analogous to the Sherwood number of mass trans- 
fer, it can be used to analyze the dissolution near the sidewalls of the fracture. According to Valueva and Purdin (2016), the Sherwood number on the fracture surfaces away from the sidewalls approaches the value provided by the Purday solution, while the Sherwood number on sidewalls and the fracture surfaces near the sidewalls approaches zero. This indicates that little dissolution occurs on the sidewalls and fracture surfaces near the sidewalls. Therefore, the dissolution will not increase the fracture width, but will increase the fracture aperture, more so when it is further away from the sidewalls. The dissolution reshapes an initial thin rectangular cross section into an elliptic cross section (Szymczak, 2013), as shown in Figures 4(d) and 5(b, c, d, and e). The fracture crosssection geometry also affects the dissolution rate, as will be discussed in the next section.

The sidewalls also limit the formation of channels. According to the stability analysis by Szymczak and Ladd (2012), the growth rate of the dissolution front instability depends on the wavelength (width) of it. Based on the relations proposed by Szymczak and Ladd (2012) and the experimental parameters (Table 1), the well-defined maximal instability growth rate is at the wavelength $\left(\lambda_{\max G}\right)$ of 11.5 to $92.1(\mathrm{~cm})$ for the tests with flow rates: 5 to $40(\mu L / s)$, respectively. When this wavelength is greater than the fracture width, the instability growth of the dissolution front is then limited by the fracture sidewalls. The instability still grows but at a lower rate, and in a not well-defined shape. The greater the difference between the fracture width and the wavelength with which the maximal growth rate is associated $\left(\lambda_{\max G}\right)$, the slower the instability will grow. Among the four fracture flow tests, those with lower flow rates have the shorter $\lambda_{\max G}$, and are more likely to result in channel formation during the limited test time. For higher flow rates, since the fracture width $1.15 \mathrm{~cm}$ is much less than $\lambda_{\max }$, the dissolution appears to be uniform in the fracture width direction as shown in Figure 5.

\subsubsection{Fracture cross-section geometry}

The channel formation and the sidewalls reshape the fracture cross-section geometry (on the $x-y$ plane in Figure 1), which as a whole also affect the transport-controlled dissolution rate $\left(k_{t}\right)$. The Sherwood numbers for fracture cross-section geometries often seen in theoretical and experimental studies are compared in Figure 7. These geometries include elliptical ducts and rectangular ducts with four-, two-, and one soluble interfaces, as used by Dijk et al. (2002); Detwiler and Rajaram (2007); Smith et al. (2013); Deng et al. (2013); W. Li et al. (2018). Although the Sherwood number in the entrance region is higher, the asymptotic values $\left(S_{h \infty}\right)$ reported by Rohsenow et al. (1998) are used for simple and direct comparison. Two special cases are the Graetz problem (Graetz, 1882) when the aspect ratio of an ellipse is one as marked with one-star sign, and the Purday problem when the aspect ratio of a rectangle is close to infinity as marked with two-star signs in Figure 7.

The fracture flow test can be used as an example to show how the fracture crosssection morphology changes the dissolution rate. The fracture cross section is initially a thin rectangle, then it becomes elliptic, due to the sidewall effect. When the channel forms, almost all the flow and dissolution occur in the channel. A schematic of this morphological process is shown in Figure 8(b). Initially, the flow and dissolution in a thin rectangular duct can be modeled by the Purday solution. When the fracture cross section becomes elliptic, the asymptotic Sherwood number is lower than that from the Purday solution, indicating a lower dissolution rate. After the formation of channels, the flow and dissolution mostly occur in the major channel (tubular). The Sherwood number for

a tubular conduit should be used, which infers an even lower dissolution rate. If the channel enlarges but maintains the tubular geometry, the dissolution rate will be constant as predicted by the extended Graetz solution. 


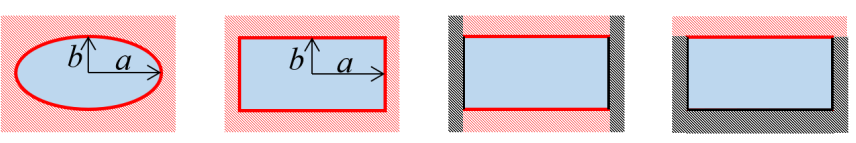

\begin{tabular}{|c|c|c|c|c|}
\hline \multirow{2}{*}{$\frac{a / b}{1}$} & \multicolumn{4}{|c|}{$S_{h \infty}$} \\
\hline & $3.66^{*}$ & 2.98 & 3.70 & 2.44 \\
\hline 2 & 3.74 & 3.39 & 4.62 & 3.19 \\
\hline 4 & 3.79 & 4.44 & 5.45 & 3.82 \\
\hline 8 & 3.73 & 5.60 & 6.32 & 4.25 \\
\hline 16 & 3.65 & 6.45 & 6.82 & 4.50 \\
\hline$\infty$ & & $7.54^{* *}$ & $7.54^{* *}$ & 4.86 \\
\hline \multicolumn{2}{|c|}{ Soluble solid } & solid & $-{ }_{\text {in }}^{\text {So }}$ & $-{ }_{\text {inte }}^{\text {Ins }}$ \\
\hline
\end{tabular}

Figure 7. Summary of asymptotic values of the Sherwood numbers for various conduits.

This example shows how the fracture cross-section geometry evolves due to dissolution and how it in turn affects the dissolution rate. This example is based on the constant flow rate assumption to decouple the hydrodynamic effect. As discussed by W. Li and Einstein (2017), the assumption of constant flow rate is reasonable under conditions such as laboratory flow tests, field injections, and some groundwater flow when the flow is controlled by other less permeable formations. However, the application of the analytical solutions is not limited by this assumption. If the hydrodynamic effect is coupled, for example flow rate changes due to the conduit geometry evolution, the analytical solutions can still be applied with the quasi-steady state assumption.

\subsection{Comparison to Reaction-Controlled Dissolution}

Comparisons of the effluent concentrations can be made between the transport-controlled dissolution and the reaction-controlled dissolution in a tube and in a fracture under constant flow rate. This comparison is used to show how the overall dissolution rates of the rock-fluid systems evolve differently for different flow and dissolution conditions. For transportcontrolled dissolution in a tube and in a fracture, the extended Graetz solution and the extended Purday solution can be used to model the effluent concentrations, respectively. For reaction-controlled dissolution in a tube and a fracture, the dissolution mass flux can be expressed as:

$$
q_{w}=k_{r}\left(C_{e q}-C_{b}\right)^{n},
$$

where $k_{r}$ is the reaction-controlled dissolution rate measured in a well-mixed laboratory system, and $n$ is the order of reaction (Lasaga, 1998). With Equation (19), the evolution of effluent concentration for reaction-controlled dissolution can be modeled. The diagram in Figure 8(a) qualitatively summarizes the results regarding the trend and the relative magnitudes of the effluent concentrations.

For transport-controlled dissolution under constant flow rate, the effluent concentration decreases for a fracture (solid blue line), while it remains constant for a tube (solid red line), as discussed in Section 5.1. For reaction-controlled dissolution under constant flow rate, the effluent concentration increases for both a tube and a fracture (dashed red and blue lines). This is because the reaction rate coefficient $k_{r}$ is constant despite the 
(a)

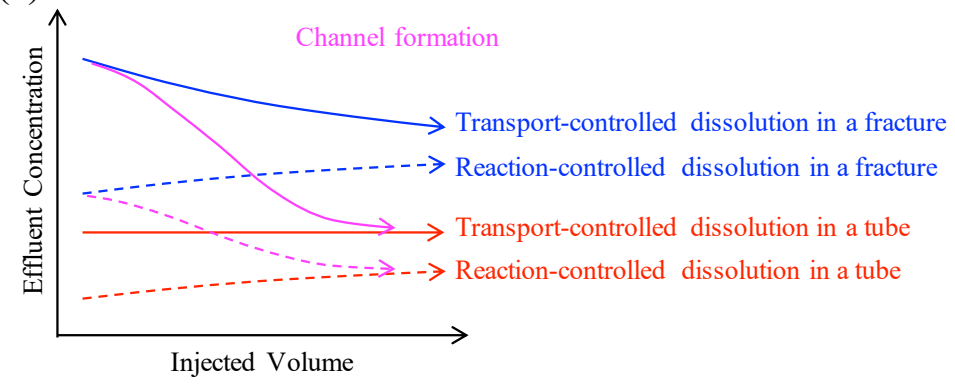

(b)

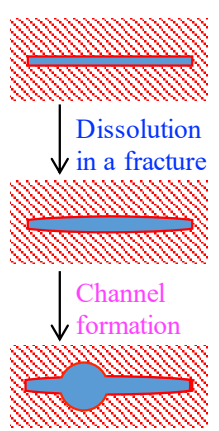

Figure 8. Evolution of effluent concentration and fracture geometry under constant flow rate. (a) Effluent concentrations under constant flow rate for transport-controlled dissolution and reaction-controlled dissolution in a tube and in a fracture. The blue and red curves represent dissolution in a fracture and a tube, respectively. The magenta lines indicate the cases for dissolution in a fracture when there is channel formation. (b) Dissolution in a fracture transforms it from a thin rectangular duct into an elliptic duct. Further dissolution may result in channels, as represented by a tube.

evolution of the fracture geometry. With the enlarging fracture aperture, the flow velocity is lower to receive more dissolved ions, thus higher effluent concentration.

If channels formed in the fracture, almost all the flow and dissolution occur in the major channels. In this case, the dissolution in fractures effectively becomes dissolution in tubes (channels), which affects the effluent concentration. Figure 8(a) uses magenta lines to indicate the evolution of the effluent concentration when channels formed in the fracture: the effluent concentration diverges from the prediction based on dissolution in a fracture and converges to the prediction based on dissolution in a tube. After the development of the channels, the effluent concentration is constant for transport-controlled dissolution (solid magenta line), while it increases for reaction-controlled dissolution (dashed magenta line). Figure 8 shows that the evolution of the conduit geometry, in turn, changes the dissolution rate of the rock-fluid system. Therefore, the evolution of the effluent concentration can be used to infer the evolution of the rock-fluid system, for example channel formation. Figure 8 can be used as a reference for laboratory studies when the flow rate is constant and the effluent concentration measurement is available.

\subsection{Implications for Theoretical, Laboratory and Field studies}

This study theoretically and experimentally investigated the transport-controlled dissolution in a planar fracture. Despite the relatively simple fracture geometry, the study provides new fundamental insights to support theoretical, laboratory and field studies regarding dissolution rates, fracture morphology, and laboratory-field rate discrepancy.

For theoretical studies, the extended Purday solution, by accounting for the entrance region and the fracture aperture heterogeneity in the flow direction, produces a more accurate transport-controlled dissolution rate than using a constant Sherwood number. The extended Purday solution can be applied to simulate flow and dissolution in rough fractures and fracture networks. In addition, the conduit cross-section geometry does make a difference for the transport-controlled dissolution rate, as indicated by the different Sherwood numbers for different cross-section geometries. For example, when channel formation is prominent in the fracture, the flow and dissolution occur in the major channel, which often has a tubular geometry. The transport-controlled dissolution rate can no longer 
be estimated by the extended Purday solution, while it should be calculated using the extended Graetz solution.

For laboratory studies on the reactive transport processes in fractures, the continuous effluent concentration measurement is an important addition to the pressure and volume measurements to monitor the evolution of the rock-fluid system (W. Li et al., 2019b). When the rock-fluid system has one soluble mineral, the ECMS can be calibrated for this mineral to continuously monitor the effluent concentration in the flow tests. When designing a fracture flow test, the sidewalls need to be accounted for in the design because they affect the local- and overall dissolution rates, fracture morphology and limit the formation channels.

The laboratory-field rate discrepancy has been a longstanding topic of discussion in the geochemical literature. Laboratory-measured dissolution rates of many minerals have been consistently found to be several orders of magnitude faster than those observed in the field (White \& Brantley, 2003; Maher et al., 2004), although it is not clear in all cases that this represents a true discrepancy in the rate constants as opposed to a failure to take into account the intrinsic differences in chemical and/or physical conditions between laboratory and field settings (Steefel et al., 2005; L. Li et al., 2008). Scale dependence, breakdown of the well-mix assumption and transport limitations have been proposed as the causes for this discrepancy (L. Li et al., 2008; Molins et al., 2019). This study explored the transport-controlled dissolution in greater details and found that the converging fracture geometry, formation of channels and the fracture sidewalls all tend to reduce the overall dissolution rate and may contribute to this laboratory-field rate discrepancy. These factors all need to be considered when investigating the laboratory-field rate discrepancy in a fractured rock-fluid system.

\section{Conclusions}

In this study, transport-controlled dissolution in a single fracture was investigated analytically and experimentally. An analytical model, the extended Purday solution, was developed to simulate dissolution in an evolving fracture, with explicit modeling of the entrance region and the converging fracture geometry. It extended the validity domain of the Purday solution from a fracture with a uniform aperture to a fracture with gradually changing aperture in the flow direction. To the authors' best knowledge, it is the first time that this solution is used for transport-controlled dissolution in a fracture. The extended Purday solution produces an accurate transport-controlled dissolution rate for numerical studies of dissolution in a rough fracture and fracture networks.

Fracture flow tests were conducted with a novel experimental setup for continuous effluent concentration measurements and 3-D fracture geometry analysis. The experimental results agreed with the predictions of the extended Purday solution regarding the fracture geometry and the decreasing overall dissolution rate. The fracture flow test results also exhibit fracture aperture heterogeneity in the width direction, such as channel formation and sidewall effect. After channel formation, most of the flow and dissolution occur in the channels, which reduces the overall dissolution rate. The sidewalls limit the formation of channels. Because of the low transport-controlled dissolution rate near the sidewalls, the fracture evolves from a thin rectangular duct to an elliptical duct. The channel formation and the sidewalls reshape the fracture cross-section geometry, which, in turn, also affects the transport-controlled dissolution rate, as indicated by the different Sherwood numbers.

The study then brings in a broader discussion on how transport-controlled dissolution compares with reaction-controlled dissolution in tubes and fractures (with and without channel formation). The evolution of the overall dissolution rate was interpreted from the effluent concentrations as dissolution changes the conduit geometry under constant 
flow rate. For transport-controlled dissolution, the overall dissolution rate decreases for a fracture, while it remains constant for a tube. For reaction-controlled dissolution, the overall dissolution rate increases for both a tube and a fracture. When channel formation is prominent, the dissolution in fractures effectively becomes dissolution in tubes, as does the evolution of the overall dissolution rate.

Overall, the extended Purday solution produces an accurate transport-controlled dissolution rate that accounts for the entrance region and fracture aperture heterogeneity in the flow direction. The predictions based on the extended Purday solution match well with the experimental results. Based on the comparison between the experimentaland modeling results, it was possible to determine the factors that affect the transportcontrolled dissolution in a fracture: channel formation, sidewalls and fracture cross-section geometry. The extended Purday solution can be applied as a rate law in future studies of reactive transport processes in natural fractures and fracture networks. The experimental methods to continuously measure effluent concentration and the findings on the effect of fracture sidewalls and cross-section geometry can be considered in future fracture flow tests to study various geological processes and engineering applications.

\section{Acknowledgments}

This work was funded by the Abu Dhabi National Oil Company. The authors thank Professor Ram Shankar Subramanian at Clarkson University for his hands-on help with the Graetz solution, which inspired this work. The authors also thank the editors and reviewers for their constructive suggestions. The experimental data supporting this work are publicly available online (http://dx.doi.org/10.17632/7xnvcbttgx.1).

\section{Appendix A Derivation of the extended Purday solution}

First, the quasi-steady state approximation is used to decouple Equations (2) and (5). The time scale for dissolution to double the aperture is $\frac{\rho_{r} \cdot \delta^{2}}{D \cdot C_{e q}} \sim 10^{5}(\mathrm{~s})$, while the time scale for the change of concentration is $\frac{\delta^{2}}{D} \sim 10^{1}(s)$. Thus the fracture geometry can be treated as constant when solving the mass conservation for the solute in the fluid. The fracture geometry at time $t$ can be used to calculate the steady state concentration $C(y, z)$ in Equation (2). This concentration can then be used to calculate the rate of change for the half aperture (Equation (5)).

Then, the axial diffusion term $D \frac{\partial^{2} C}{\partial z^{2}}$ can be neglected when the axial advection is much faster than axial diffusion. This is often the case when the Péclet number $P_{e}=$ $\frac{\bar{u}_{z} \cdot 4 \delta}{D}$ is greater than 100 (Bird et al., 2015). With these two simplifications, the partial differential equations needed to be solved become:

$$
\begin{aligned}
0 & =-u_{z} \cdot \frac{\partial C}{\partial z}-u_{y} \cdot \frac{\partial C}{\partial y}+D \frac{\partial^{2} C}{\partial y^{2}} ; \\
\frac{\partial \delta}{\partial t} & =-\left.\frac{1}{\rho_{r}} \cdot D \frac{\partial C}{\partial y}\right|_{y=\delta},
\end{aligned}
$$

with the boundary and initial conditions listed in Equations (3) and (6), respectively. The problem described by Equations (A1a) and (3) is analogous to the heat transfer problem: laminar flow induced convection in converging or diverging planar ducts. The solution process by Lee and Zerkle (1969); Özişik et al. (1982) for the heat transfer problem are adopted in this paper for the transport-controlled dissolution in a converging fracture. First, dimensionless variables are defined: 


$$
Z_{f}=\frac{z}{\delta_{1} P_{e 1}}=\frac{D z}{4 \delta_{1}^{2} \bar{u}_{z 1}}, \quad P_{e 1}=\frac{\bar{u}_{z 1} \cdot 4 \delta_{1}}{D}, \quad \Delta=\frac{\delta}{\delta_{1}}, \text { and } \theta=\frac{C_{e q}-C}{C_{e q}} .
$$

Then, dimensionless coordinates are defined:

$$
\begin{aligned}
\eta & =\frac{y}{\delta} \\
\xi & =\int_{0}^{Z_{f}} \frac{1}{\Delta} d Z_{f}
\end{aligned}
$$

The dimensionless coordinates transform the solution domain from an irregular shape bounded by $(0<y<\delta(z), 0<z<L)$ to a rectangle bounded by $(0<\eta<1,0<\xi<$

$\left.\int_{0}^{Z_{f}} \frac{1}{\Delta} d z\right)$. By using the dimensionless coordinates, Equation (A1a) and its boundary conditions become:

$$
\begin{aligned}
\frac{3}{8}\left(1-\eta^{2}\right) \cdot \frac{\partial \theta}{\partial \xi} & =\frac{\partial^{2} \theta}{\partial \eta^{2}} ; \\
\left.\theta\right|_{\xi=0} & =1 ; \\
\left.\theta\right|_{\eta=1} & =0 ; \\
\left.\frac{\partial \theta}{\partial \eta}\right|_{\eta=0} & =0 .
\end{aligned}
$$

This equation is the same as the dimensionless form of the governing equation for the Purday problem. Thus the Purday solution can be applied to solve Equation (A4). Furthermore, since the derivation does not depend on the prescribed aperture profile $\delta(z)$, the solution holds as long as the flow velocity profile (Equation (4)) is valid. This is the case for fully developed laminar flow in a fracture with gradually changing aperture. The Purday solution can now be extended to transport-controlled dissolution in a fracture with gradually changing aperture in the flow direction. The extended Purday solution produces the dimensionless concentration profile in the fracture:

$$
\theta=\sum_{n=1}^{\infty} \frac{-2 \phi_{n}}{\left.\lambda_{n}\left(\frac{\partial \phi_{n}}{\partial \lambda_{n}}\right)\right|_{\eta=1}} \exp \left(-\frac{8}{3} \lambda_{n}^{2} \xi\right)
$$

where $\lambda_{n}$ and $\phi_{n}$ are eigenvalues and eigenfunctions of Equation (A4) (Brown, 1960). Equation (A5) provides the dimensionless concentration profile in the fracture in the dimensionless coordinates $(\theta=\theta(\eta, \xi))$. Based on Equation (A5), the dimensionless bulk concentration $\theta_{b}$ and the Sherwood number $S_{h}$ can be expressed as:

$$
\begin{aligned}
\theta_{b}(\xi) & =\sum_{n=1}^{\infty} \frac{\left.3\left(\frac{\partial \phi_{n}}{\partial \eta}\right)\right|_{\eta=1}}{\left.\lambda_{n}^{3}\left(\frac{\partial \phi_{n}}{\partial \lambda_{n}}\right)\right|_{\eta=1}} \exp \left(-\frac{8}{3} \lambda_{n}^{2} \xi\right), \\
S_{h}(\xi) & =\frac{8}{3} \cdot \frac{\sum_{n=1}^{\infty} \frac{\left.\left(\frac{\partial \phi_{n}}{\partial \phi_{n}}\right)\right|_{\eta=1}}{\left.\lambda_{n}\left(\frac{\partial \phi_{n}}{\partial \lambda_{n}}\right)\right|_{\eta=1}} \exp \left(-\frac{8}{3} \lambda_{n}^{2} \xi\right)}{\sum_{n=1}^{\infty} \frac{\left.\left(\frac{\partial \phi_{n}}{\partial \eta}\right)\right|_{\eta=1}}{\left.\lambda_{n}^{3}\left(\frac{\partial \phi_{n}}{\partial \lambda_{n}}\right)\right|_{\eta=1}} \exp \left(-\frac{8}{3} \lambda_{n}^{2} \xi\right)} .
\end{aligned}
$$




\section{References}

Barron, A., Hendrickson, A., \& Wieland, D. (1962). The effect of flow on acid reactivity in a carbonate fracture. Journal of Petroleum Technology, 14(04), 409415.

Berkowitz, B. (2002). Characterizing flow and transport in fractured geological media: A review. Advances in Water Resources, 25(8), 861 - 884.

Bird, R. B., Stewart, W. E., Lightfoot, E. N., \& Klingenberg, D. J. (2015). Introductory Transport Phenomena. Wiley Global Education.

Brown, G. M. (1960). Heat or mass transfer in a fluid in laminar flow in a circular or flat conduit. AIChE Journal, 6(2), 179-183.

Brantley, S. L., Kubicki, J. D., \& White, A. F. (2008). Kinetics of Water-Rock Interaction. Springer.

Brunet, J.-P. L., Li, L., Karpyn, Z. T., \& Huerta, N. J. (2016). Fracture opening or self-sealing: Critical residence time as a unifying parameter for cement$\mathrm{CO}_{2}$-brine interactions. International Journal of Greenhouse Gas Control, 47 , $25-37$.

Budek, A., \& Szymczak, P. (2012). Network models of dissolution of porous media. Physical Review E, 86(5), 056318.

Cao, P., Karpyn, Z. T., \& Li, L. (2015). Self-healing of cement fractures under dynamic flow of $\mathrm{CO}_{2}$-rich brine. Water Resources Research, 51 (6), 4684-4701.

Cao, P., Karpyn, Z. T., \& Li, L. (2016). The role of host rock properties in determining potential $\mathrm{CO}_{2}$ migration pathways. International Journal of Greenhouse Gas Control, 45, 18-26.

Cooper, A., \& Gutiérrez, F. (2013). Dealing with gypsum karst problems: Hazards, environmental issues, and planning. In Treatise on Geomorphology (p. 451 462). San Diego: Academic Press.

Daccord, G. (1987). Chemical dissolution of a porous medium by a reactive fluid. Physical Review Letters, 58(5), 479.

Deng, H., Ellis, B. R., Peters, C. A., Fitts, J. P., Crandall, D., \& Bromhal, G. S. (2013). Modifications of carbonate fracture hydrodynamic properties by $\mathrm{CO}_{2}$ acidified brine flow. Energy \& Fuels, 27(8), 4221-4231.

Deng, H., Fitts, J. P., \& Peters, C. A. (2016). Quantifying fracture geometry with $\mathrm{x}$-ray tomography: Technique of iterative local thresholding (TILT) for 3D image segmentation. Computational Geosciences, 20(1), 231-244.

Deng, H., Molins, S., Trebotich, D., Steefel, C., \& DePaolo, D. (2018). Pore-scale numerical investigation of the impacts of surface roughness: Upscaling of reaction rates in rough fractures. Geochimica et Cosmochimica Acta, 239, 374-389.

Deng, H., \& Peters, C. A. (2019). Reactive transport simulation of fracture channelization and transmissivity evolution. Environmental Engineering Science, 36(1), 90-101.

Deng, H., \& Spycher, N. (2019). Modeling reactive transport processes in fractures. Reviews in Mineralogy and Geochemistry, 85(1), 49-74.

Detwiler, R. L. (2008). Experimental observations of deformation caused by mineral dissolution in variable-aperture fractures. Journal of Geophysical Research: Solid Earth, 113(B8).

Detwiler, R. L. (2010). Permeability alteration due to mineral dissolution in partially saturated fractures. Journal of Geophysical Research: Solid Earth, 115(B9).

Detwiler, R. L., Glass, R. J., \& Bourcier, W. L. (2003). Experimental observations of fracture dissolution: The role of peclet number on evolving aperture variability. Geophysical Research Letters, 30(12).

Detwiler, R. L., \& Rajaram, H. (2007). Predicting dissolution patterns in variable aperture fractures: Evaluation of an enhanced depth-averaged computational model. Water Resources Research, 43(4). 
Dijk, P. E., Berkowitz, B., \& Yechieli, Y. (2002). Measurement and analysis of dissolution patterns in rock fractures. Water Resources Research, 38(2), 5-1.

Dobson, P. F., Kneafsey, T. J., Sonnenthal, E. L., Spycher, N., \& Apps, J. A. (2001). Experimental and numerical simulation of dissolution and precipitation: Implications for fracture sealing at yucca mountain, nevada. Journal of Contaminant Hydrology, 62(LBNL-48872).

Dreybrodt, W. (2012). Processes in Karst Systems: Physics, Chemistry, and Geology. Springer Science \& Business Media.

Dreybrodt, W., \& Gabrovšek, F. (2019). Dynamics of wormhole formation in fractured limestones. Hydrology and Earth System Sciences, 23(4), 1995-2014.

Durham, W. B., Bourcier, W. L., \& Burton, E. A. (2001). Direct observation of reactive flow in a single fracture. Water Resources Research, 37(1), 1-12.

Elkhoury, J. E., Detwiler, R. L., \& Ameli, P. (2015). Can a fractured caprock selfheal? Earth and Planetary Science Letters, 417, 99-106.

Ellis, B. R., Fitts, J. P., Bromhal, G. S., McIntyre, D. L., Tappero, R., \& Peters, C. A. (2013). Dissolution-driven permeability reduction of a fractured carbonate caprock. Environmental Engineering Science, 30(4), 187-193.

Fitts, J. P., \& Peters, C. A. (2013). Caprock fracture dissolution and $\mathrm{CO}_{2}$ leakage. Reviews in Mineralogy and Geochemistry, 77(1), 459-479.

Fredd, C. N., \& Fogler, H. S. (1998). Influence of transport and reaction on wormhole formation in porous media. AIChE journal, 44 (9), 1933-1949.

Graetz, v. L. (1882). Ueber die wärmeleitungsfähigkeit von flüssigkeiten. Annalen der Physik, 254(1), 79-94.

Grodzki, P., \& Szymczak, P. (2019). Reactive-infiltration instability in radial geometry: From dissolution fingers to star patterns. Physical Review E, 100, 033108 .

Jeschke, A. A., Vosbeck, K., \& Dreybrodt, W. (2001). Surface controlled dissolution rates of gypsum in aqueous solutions exhibit nonlinear dissolution kinetics. Geochimica et Cosmochimica Acta, 65(1), 27-34.

Jones, T. A., \& Detwiler, R. L. (2016). Fracture sealing by mineral precipitation: The role of small-scale mineral heterogeneity. Geophysical Research Letters, 43(14), 7564-7571.

Jung, H. B., Kabilan, S., Carson, J. P., Kuprat, A. P., Um, W., Martin, P., \& Stephens, S. (2014). Wellbore cement fracture evolution at the cement-basalt caprock interface during geologic carbon sequestration. Applied Geochemistry, 47, 1-16.

Kaufmann, G., Gabrovšek, F., \& Romanov, D. (2014). Deep conduit flow in karst aquifers revisited. Water Resources Research, 50(6), 4821-4836.

Lasaga, A. C. (1998). Kinetic Theory in the Earth Sciences. Princeton University Press.

Lee, D. G., \& Zerkle, R. D. (1969). The effect of liquid solidification in a parallel plate channel upon laminar-flow heat transfer and pressure drop. Journal of Heat Transfer, 91(4), 583-585.

Li, L., Steefel, C. I., \& Yang, L. (2008). Scale dependence of mineral dissolution rates within single pores and fractures. Geochimica et Cosmochimica Acta, 72 (2), 360-377.

Li, W., \& Einstein, H. H. (2017). Theoretical and numerical investigation of the cavity evolution in gypsum rock. Water Resources Research, 53(11), 9988-10001.

Li, W., Einstein, H. H., \& Germaine, J. T. (2019a). An experimental study of matrix dissolution and wormhole formation using gypsum core flood tests: 1. permeability evolution and wormhole geometry analysis. Journal of Geophysical Research: Solid Earth, 124(11), 11055-11073.

Li, W., Einstein, H. H., \& Germaine, J. T. (2019b). An experimental study of matrix dissolution and wormhole formation using gypsum core flood tests: 2 . dissolution kinetics and modeling. Journal of Geophysical Research: Solid 
Earth, 124(11), 11074-11088.

Li, W., Opolot, M., Sousa, R., \& Einstein, H. (2018). Transport-controlled dissolution in underground cavities: An experimental validation of the extended graetz solution. In 52nd US Rock Mechanics/Geomechanics Symposium.

Lienhard, J. H. (2011). A Heat Transfer Textbook. Mineola, N.Y.: Dover Publications.

Liu, J., Polak, A., Elsworth, D., \& Grader, A. (2005). Dissolution-induced preferential flow in a limestone fracture. Journal of Contaminant Hydrology, 78(1-2), $53-70$.

Liu, S.-T., \& Nancollas, G. (1971). The kinetics of dissolution of calcium sulfate dihydrate. Journal of Inorganic and Nuclear Chemistry, 33(8), 2311-2316.

MacQuarrie, K. T., \& Mayer, K. U. (2005). Reactive transport modeling in fractured rock: A state-of-the-science review. Earth-Science Reviews, 72(3-4), 189-227.

Maher, K., DePaolo, D. J., \& Lin, J. C.-F. (2004). Rates of silicate dissolution in deep-sea sediment: In situ measurement using ${ }^{234} \mathrm{U} /{ }^{238} \mathrm{U}$ of pore fluids. Geochimica et Cosmochimica Acta, 68(22), 4629-4648.

Molins, S., Trebotich, D., Arora, B., Steefel, C. I., \& Deng, H. (2019). Multi-scale model of reactive transport in fractured media: Diffusion limitations on rates. Transport in Porous Media, 128(2), 701-721.

Noiriel, C., \& Deng, H. (2018). Evolution of planar fractures in limestone: The role of flow rate, mineral heterogeneity and local transport processes. Chemical Geology, 497, 100-114.

Noiriel, C., Luquot, L., Madé, B., Raimbault, L., Gouze, P., \& Van Der Lee, J. (2009). Changes in reactive surface area during limestone dissolution: An experimental and modelling study. Chemical Geology, 265(1-2), 160-170.

Osselin, F., Kondratiuk, P., Budek, A., Cybulski, O., Garstecki, P., \& Szymczak, P. (2016). Microfluidic observation of the onset of reactive-infitration instability in an analog fracture. Geophysical Research Letters, 43(13), 6907-6915.

Özişik, M., Trepp, C., \& Egolf, H. (1982). Laminar forced convection in converging or diverging planar symmetric ducts. International Journal of Heat and Mass Transfer, 25(10), 1477-1480.

Polak, A., Elsworth, D., Liu, J., \& Grader, A. S. (2004). Spontaneous switching of permeability changes in a limestone fracture with net dissolution. Water Resources Research, 40(3).

Purday, H. F. P. (1949). Streamline flow. Constable.

Pyrak-Nolte, L. J., DePaolo, D. J., \& Pietraß, T. (2015). C Controlling subsurface fractures and fluid flow: A basic research agenda (Tech. Rep.). USDOE Office of Science (SC)(United States).

Quiggin, N. (2011). Inspect-X User Manual. Nikon Metrology, Hertfordshire, England.

Rohsenow, W. M., Hartnett, J. P., \& Cho, Y. I. (1998). Handbook of Heat Transfer (Vol. 3). McGraw-Hill New York.

Russ, J. C. (2016). The Image Processing Handbook. CRC press.

Schenk, J. (1955). A problem of heat transfer in laminar flow between parallel plates. Applied Scientific Research, 5(2), 241-244.

Schenk, J., \& Dumore, J. (1953). Heat transfer in laminar flow through cylindrical tubes. Applied Scientific Research, Section A, 4(1), 39-51.

Schenk, J., \& Han, B. S. (1967). Heat transfer from laminar flow in ducts with elliptic cross-section. Applied Scientific Research, 17(2), 96-114.

Sellars, J. R., Tribus, M., \& Klein, J. (1954). Heat transfer to laminar flow in a round tube or flat conduit: the Graetz problem extended (Tech. Rep.). Wright Air Development Center.

Shah, R. K., \& London, A. L. (1978). Laminar Flow Forced Convection in Ducts: A Source Book for Compact Heat Exchanger Analytical Data. Academic press. 
Singurindy, O., \& Berkowitz, B. (2004). Dedolomitization and flow in fractures. Geophysical Research Letters, $31(24)$.

Singurindy, O., \& Berkowitz, B. (2005). The role of fractures on coupled dissolution and precipitation patterns in carbonate rocks. Advances in Water Resources, $28(5), 507-521$.

Smith, M. M., Sholokhova, Y., Hao, Y., \& Carroll, S. A. $\quad$ (2013). $\quad \mathrm{CO}_{2}$-induced dissolution of low permeability carbonates. Part I: Characterization and experiments. Advances in Water Resources, 62, 370-387.

Starchenko, V., \& Ladd, A. J. (2018). The development of wormholes in laboratoryscale fractures: Perspectives from three-dimensional simulations. Water Resources Research, 54(10), 7946-7959.

Steefel, C. I., DePaolo, D. J., \& Lichtner, P. C. (2005). Reactive transport modeling: An essential tool and a new research approach for the earth sciences. Earth and Planetary Science Letters, 240(3-4), 539-558.

Szymczak, P., \& Ladd, A. (2009). Wormhole formation in dissolving fractures. Journal of Geophysical Research: Solid Earth, 114(B6).

Szymczak, P., \& Ladd, A. J. (2011). The initial stages of cave formation: Beyond the one-dimensional paradigm. Earth and Planetary Science Letters, 301 (3-4), 424-432.

Szymczak, P., \& Ladd, A. J. (2012). Reactive-infiltration instabilities in rocks: Fracture dissolution. Journal of Fluid Mechanics, 702, 239-264.

Szymczak, P. (2013). From slots to tubes: The influence of dimensionality on fracture dissolution models. Acta Geophysica, 61(6), 1556-1572.

Upadhyay, V. K., Szymczak, P., \& Ladd, A. J. (2015). Initial conditions or emergence: What determines dissolution patterns in rough fractures? Journal of Geophysical Research: Solid Earth, 120(9), 6102-6121.

Valueva, E., \& Purdin, M. (2016). Heat exchange at laminar flow in rectangular channels. Thermophysics and Aeromechanics, $23(6), 857-867$.

Walsh, S. D., Du Frane, W. L., Mason, H. E., \& Carroll, S. A. (2013). Permeability of wellbore-cement fractures following degradation by carbonated brine. Rock Mechanics and Rock Engineering, 46(3), 455-464.

Wen, H., Li, L., Crandall, D., \& Hakala, A. (2016). Where lower calcite abundance creates more alteration: enhanced rock matrix diffusivity induced by preferential dissolution. Energy \& Fuels, 30(5), 4197-4208.

White, A. F., \& Brantley, S. L. (2003). The effect of time on the weathering of silicate minerals: why do weathering rates differ in the laboratory and field? Chemical Geology, 202(3-4), 479-506. 